\begin{tabular}{|l|l|l||}
\hline \multicolumn{2}{|c|}{ PublisherInfo } \\
\hline \hline PublisherName & $:$ & BioMed Central \\
\hline \hline PublisherLocation & $:$ & London \\
\hline \hline PublisherImprintName & $:$ & BioMed Central \\
\hline \hline
\end{tabular}

\title{
Multigene expression patterns predict metastatic behavior
}

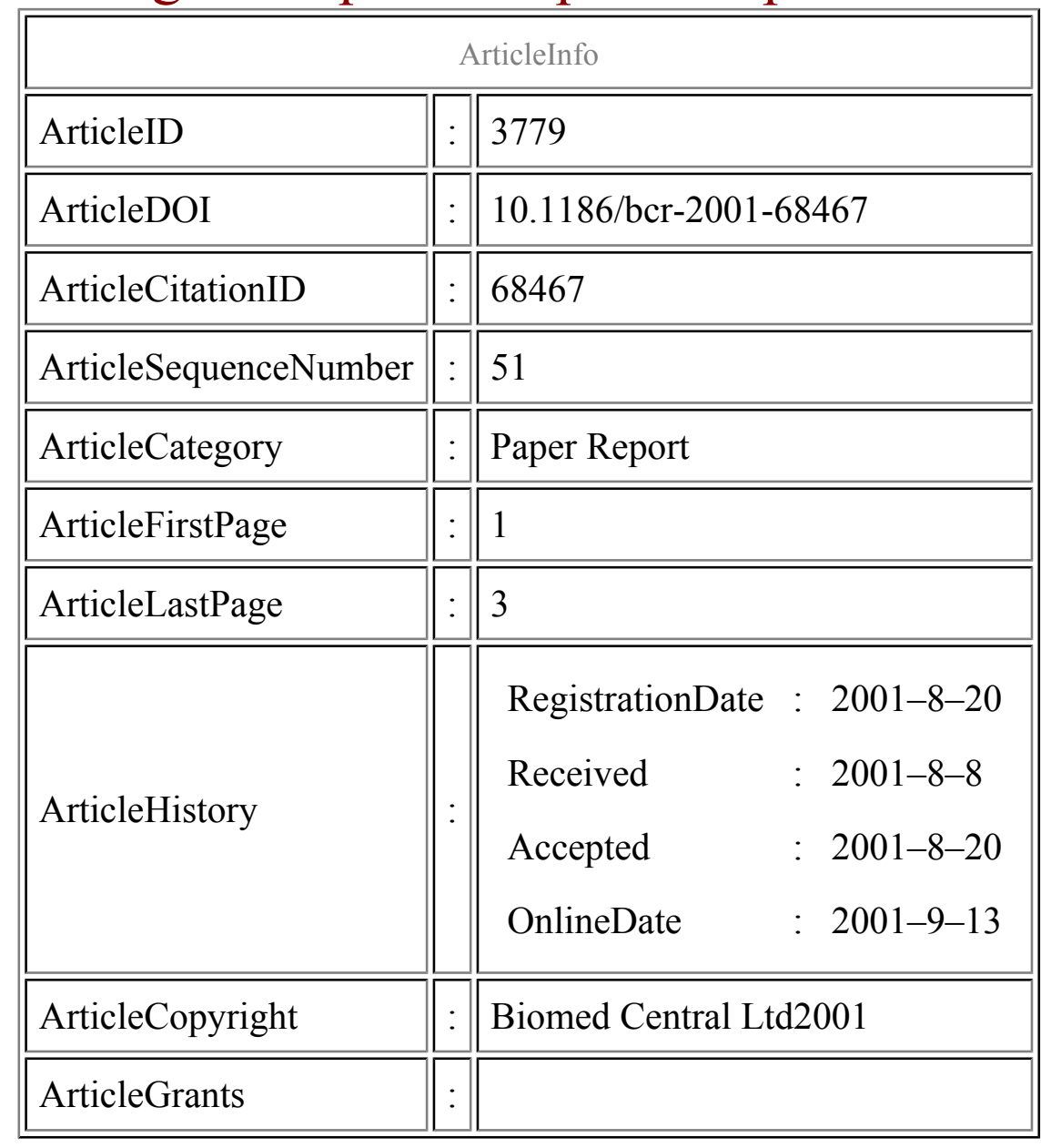




\begin{tabular}{|l|l|l|l|}
\hline ArticleContext & $:$ & 1305833 \\
\hline
\end{tabular}

Karen L Schmeichel, ${ }^{\text {Aff1 }}$

Aff1 Lawrence Berkeley National Laboratory, Berkeley, California, USA

\section{Keywords}

\section{Context}

Comparative gene expression analysis of clinically derived breast cancer specimens or established breast cancer cell lines is a promising approach for the identification of critical breast-cancer-related gene clusters. The aim of this study was to use array technology to identify patterns that could be predictive for a specific metastatic behavior (i.e. weakly or highly invasive), as measured by a number of in vitro assays. As proof-of-principle for future diagnostic scenarios, the authors proposed to test the predictive capacity of these "consensus expression profiles" in the context of other breast cancer cell lines whose metastatic behavior had not been systematically characterized in vitro.

\section{Significant findings}

A 24-gene cassette was identified that reproducibly distinguished between weakly invasive or highly invasive cell lines. Consistent with the proposed hypothesis, uncharacterized cell lines with the weakly invasive cassette showed a weakly invasive phenotype. Likewise, the highly invasive consensus was a reasonable indicator of a highly metastatic phenotype. Three single genes (encoding keratin 19, vimentin and fos-related antigen-1) were identified as reliable indicators of metastatic potential.

\section{Comments}

The development of strategies to translate array data into meaningful diagnostic and therapeutic tools is still in its infancy. The authors suggest that, although a few individual genes were identified as reliable indicators of metastatic potential, the use of multigene expression patterns is likely to be more 
effective in developing array-based prognostic tools in the context of more complex clinically derived samples. This paper makes a significant contribution towards this goal by recognizing that predictive markers will be most useful if their predictive capacity can be verified experimentally prior to use in a clinical setting. Here we are provided with a systematic proof-of-principle study that convincingly links gene expression profiles with cellular behavior. The limitation of the approach described here stems from our less-than-perfect ability to model metastatic potential in vitro. Out of three commonly used in vitroassays, colony morphology on Matrigel was cited as the most reproducible single measurement of metastatic phenotype. Thus it is surprising that a more detailed analysis of colony morphology, including examination of colony organization in cross-section, was not described.

\section{Methods}

cDNA hybridization, Pearson correlation coefficients, northern blot, RT-PCR, chemoinvasion and migration assays, Matrigel outgrowth

\section{Additional information}

\section{References}

1. Zajchowski DA, Bartholdi MF, Gong Y, Webster L, Liu H-L, Munishkin A, Beauheim C, Harvey S, Ethier SP, Johnson PH: Identification of gene expression profiles that predict the aggressive behavior of breast cancer cells. Cancer Res . 2001, 61: 5168-5178. 